\title{
Polyaniline-doped benzene sulfonic acid/epoxy resin composites: structural, morphological, thermal and dielectric behaviors
}

\begin{abstract}
Belkacem Belaabed ${ }^{1}$, Saad Lamouri ${ }^{1}$, Nacera Naar ${ }^{1}$, Patrice Bourson ${ }^{2}$ and Sidi Ould Saad Hamady ${ }^{2}$
Conducting polymer composites, which are simply physical mixtures of an insulating polymer matrix and intrinsically conducting polymers, are promising new materials for various applications such as antistatic coatings, shielding and electromagnetic absorbers. In this context, a novel conducting composite was successfully produced. It is based on epoxy resin and polyaniline (PANI) doped in benzene sulfonic acid, which was used as conducting filler. The effect of PANI loading levels on the structural, morphological, thermal, electrical and dielectric properties was explored using techniques, such as Raman, Fourier transform infrared and ultraviolet-visible-NIR spectroscopy, X-ray diffraction, atomic force microscopy, scanning electron microscopy, thermogravimetric analysis and differential scanning calorimetry. The electrical behavior and morphology of the synthesized PANI revealed disorder and defects. In addition, as the applied voltage is increased, the current through the sample increases rapidly. The conductivity and dielectric properties were also investigated at room temperature in the frequency range of $1 \mathrm{MHz}-$ $1 \mathrm{GHz}$. The dielectric constant was shown to increase with increased loading at low frequencies and then decreases rapidly, reaching a constant value at higher frequencies. In addition, the AC conductivity of the prepared composites increases with the addition of PANI and is higher at high frequencies. Furthermore, the stability of the composites was found to be influenced by increasing the amount of PANI filler in the matrix.
\end{abstract}

Polymer Journal (2010) 42, 546-554; doi:10.1038/pj.2010.41; published online 2 June 2010

Keywords: conducting polymer composite; dielectric; PANI; epoxy resin

\section{INTRODUCTION}

With increases in electromagnetic pollution and the wide use of commercial products based on electronic devices that function in different wavelength ranges, there is a growing interest in electromagnetic absorbers and shielding. Advanced composite materials with high dielectric constants and high conductivity can achieve good electromagnetic properties that can be used for various applications. ${ }^{1,2}$ For this reason, over the past decades, polymer-matrix composites containing conductive fillers have been extensively studied due to their growing demand in advanced technology and electronic systems. ${ }^{3}$ They are used in the form of thin layers produced with dense materials containing various products with high electric permittivity and/or magnetic permeability, such as metal oxides or carbon black and so on, dispersed in a diverse polymeric matrix. However, these products are considered as heterogeneous disordered systems; they represent $60-90 \%$ of the system's weight, ${ }^{4}$ eliminating the insulating characteristics of the final material. They are very brittle when exposed to the sun or moisture and corrode, thereby reducing the conductivity and imposing high maintenance costs. These disadvantages thus limit their use, particularly in aeronautics. Intrinsically conducting polymers with their unique properties (lightweight, low cost, ease of synthesis, good electromagnetic properties and corrosion resistance) are promising products to replace these fillers. PANI is one of the most intensively studied conducting polymers; it is a highly attractive candidate for these applications due to its facile synthesis, good electrical properties and environmental/chemical stability, ${ }^{5,6}$ and its conductivity is improved by the doping process. However, due to the poor mechanical properties of PANI, it must be mixed with a suitable matrix. ${ }^{7}$ The dispersion of PANI nanofiller in an insulating polymer matrix (thermoplastic or thermosetting) produces different composites that can absorb and reflect electromagnetic radiation by changing its dielectric constant after interaction with microwave-range photons. Epoxy resins cured by many agents such as amines, Lewis acid and anhydrides are widely used as coatings, adhesives and insulators in the industry due to their good mechanical properties, including a high modulus, good electrical and thermal properties and excellent cohesiveness as compared with many other materials. ${ }^{8}$ New materials such as conducting polymer composites can be developed by combining the good mechanical properties of epoxy resin with the high performance and electrical properties of PANI.

${ }^{1}$ Laboratory of Macromolecular Chemistry, Military Polytechnic School, Algiers, Algeria and ${ }^{2}$ Laboratory of Optical Materials, Photonic and Systems, University Paul Verlaine Metz and SUPELEC, Metz, France

Correspondence: Professor S Lamouri, Laboratory of Macromolecular Chemistry, EMP, BP. 17, Bordj El Bahri, Algiers 16111, Algeria.

E-mail: lamourisaad@gmail.com

Received 9 December 2009; revised 11 April 2010; accepted 12 April 2010; published online 2 June 2010 
In this study, PANI/epoxy resin composites with anhydride mixed with a catalyst as a hardener were prepared with different amounts of PANI. The PANI was prepared directly by conventional oxidative polymerization methods using BSA as the doping agent. The structure of the samples was investigated by Fourier transform infrared (FTIR), Raman and ultraviolet-visible (UV-Vis)-NIR spectroscopy and X-ray diffraction (XRD). The frequency dependency of the conductivity and dielectric properties of the different composites was also studied in the range of $1 \mathrm{MHz}-1 \mathrm{GHz}$ at room temperature. The influence of the PANI loading levels on dielectric properties of the PANI/epoxy composites was explored. Scanning electron microscopy (SEM) and atomic force microscopy (AFM) were used to characterize the morphology and topography of the samples. To investigate the relationship between the PANI and composite properties, the thermal behavior of these composites was investigated by thermogravimetric analysis (TGA) and differential scanning calorimetry, respectively, in the temperature range of $20-600{ }^{\circ} \mathrm{C}$. The electrical resistivity was measured using a four-probe technique.

\section{EXPERIMENTAL PROCEDURE}

\section{Materials}

Commercial Medapoxy Inject 830 (epoxy resin: element A) was obtained from Algerian Granitex (Oueud Smar, Algiers, Algeria). Aniline (99\% purity), $90 \%$ BSA, hexahydrophtalic anhydride and $\mathrm{BF}_{3}$ complex were purchased from S.A.R.L. Sigma-Aldrich CHIMIE (St Quentin Fallavier CDX, France). Ethanol (96\%) and tetrahydrofuran were supplied from Biochem (Paris, France), and ammonium peroxydisulfate (99\%) was purchased from Prolabo (Paris, France). All these products were used without purification

\section{Preparation of PANI salt}

In a glass reactor with double walls maintained at $-17^{\circ} \mathrm{C}$ by a cooling system, $4.9 \mathrm{ml}$ of aniline in $75 \mathrm{ml}$ of distilled water was mixed with $0.09 \mathrm{M}$ of BSA for $2 \mathrm{~h}$ under constant mechanical stirring until a homogenous milky dispersion developed. When the $\mathrm{pH}$ of the solution approached 1 and the cooling temperature reached $-17^{\circ} \mathrm{C}$, we dropwise added the oxidizing solution ammonium peroxydisulfate $\left(\left(\mathrm{NH}_{4}\right)_{2} \mathrm{~S}_{2} \mathrm{O}_{8}\right)$ prepared at a report/ratio of concentration [oxidant]/[aniline] equal to 1.15 and cooled at the same temperature. Over $2 \mathrm{~h}$, we observed the formation of a dark green precipitate. The polymerization reaction continued for $24 \mathrm{~h}$ under mechanical stirring; then, the mixture was filtered, and the filter was subsequently washed several times with distilled water and ethanol to remove by-products until the extracted solution was colorless. The purified PANI-BSA powder was dried under vacuum at $70^{\circ} \mathrm{C}$ for $48 \mathrm{~h}$.

\section{Composite preparation}

PANI-doped BSA was dispersed in tetrahydrofuran as the solvent at room temperature using an ultrasonic bath for $3 \mathrm{~h}$, followed by magnetic stirring to improve the dispersion quality and to obtain nanoparticles. Then, epoxy resin was added to the above-mentioned solution at a continuous moderate stirring speed and was heated at $60^{\circ} \mathrm{C}$ for $4 \mathrm{~h}$ to remove the solvent residues that have an evaporation point below the crosslinking temperature and to assure high dispersion and a homogeneous mixture. The weight contents of the PANI-BSA in the PANI/epoxy resin composites were 1, 5, 10, 15, 20 and $30 \mathrm{wt} \%$, respectively. After the solvent evaporated, $81.5 \mathrm{~g}$ of the curing agent with a catalyst was added for $100 \mathrm{~g}$ of epoxy resin. The obtained mixture was immediately poured into appropriate molds to obtain a film with a thickness in the order of $300 \mu \mathrm{m}$. Through spin coating, a part of the mixture was deposited on silicon and glass using a syringe to obtain a film with a thickness ranging from 50 to $100 \mu \mathrm{m}$ for SEM and AFM analysis. The films were subjected to crosslinking steps in a thermostatic oven under vacuum, first baking at $80^{\circ} \mathrm{C}$ for $4 \mathrm{~h}$ and then post-curing at $120^{\circ} \mathrm{C}$ for $24 \mathrm{~h}$.

\section{Instrumental analysis}

Raman spectra were collected using an Aramis Horiba Jobin-Yvon spectrometer (HORIBA Jobin Yvon S.A.S. Raman Division, Villeneuve D'ascq, France) with a 785-nm laser diode, in order to reveal the ring characteristics of samples without a specific preparation. The Raman shift range was between 200 and $2200 \mathrm{~cm}^{-1}$, at a resolution of $2 \mathrm{~cm}^{-1}$. UV-Vis-NIR spectra were measured with a Varian UV spectrophotometer (Varian, Palo Alto, CA, USA). The PANIdoped BSA was dispersed in $\mathrm{KBr}$ and compressed into pellets, and a thin film of the PANI/epoxy resin composites placed between two $\mathrm{KBr}$ discs was studied using a Shimadzu FTIR 84005 spectrophotometer (Shimadzu Corporation, Nakagyo-ku, Kyoto, Japan). XRD analysis of the samples was performed at room temperature using a Brucker X-Ray diffractometer (Bruker AXS S.A.S., Champs-sur-Marne, France) with $\mathrm{Cu} \mathrm{K} \alpha$ radiation at a wavelength of $1.5418 \AA$, operating at $40 \mathrm{kV}$ and $40 \mathrm{~mA}$ in the range of $2 \theta=10-80^{\circ}$. Morphological analysis was carried out with a JEOL JSM 5800 scanning electron microscope (JEOL, Tokyo, Japan) operating between 5 and $20 \mathrm{kV}$ and 35-50 $\mu \mathrm{A}$. To avoid the effect of electric charge on the surface and to facilitate the flow of the electrons, the samples were coated with a thin layer of gold. An AFM apparatus from Pacific Nanotechnology (Santa Clara, CA, USA) was used to reveal the surface topography at room temperature using the tapping-mode close contact. The thermal stability of the samples was investigated by thermogravimetric (TGA) measurements that were carried out under a nitrogen purge with $20 \mathrm{ml} \mathrm{min}^{-1}$ as the flow rate and a heating rate of $5^{\circ} \mathrm{C} \mathrm{min}^{-1}$ up to $600{ }^{\circ} \mathrm{Cmin}^{-1}$ using a NETZSCH STA 449C Jupiter instrument (Erich NETZSCH $\mathrm{GmbH}$ \& Co. Holding KG, Selb, Germany). In addition, the thermal behavior of PANI was investigated using a differential scanning calorimetry type NETZSCH STA 449C (204 F1) Phoenix, operating in the dynamic scanning mode with a constant nitrogen flow of $20 \mathrm{mlmin}^{-1}$ and a heating rate of $5^{\circ} \mathrm{Cmin}^{-1}$ from 20 to $550^{\circ} \mathrm{C}$. The electrical conductivity of the different samples was measured at room temperature with a four-probe method using a Signatone 1160 series probe station (Signatone Corporation, Gilroy, CA, USA). Pellets with a thickness of $0.5-0.6 \mathrm{~mm}$ of PANI powder were prepared, and thin contact points of gold were deposited to ensure good contact between the sample and the electrode; the DC conductivity was calculated from the current-voltage dependence. The AC conductivity and dielectric behavior of thin composite films with thickness ranging from 300 to $600 \mu \mathrm{m}$, coated with silver on both sides, were measured with an HP4191A RF impedance meter (Agilent Technologies, Englewood, CO, USA) at frequencies ranging from $1 \mathrm{MHz}$ to $1 \mathrm{GHz}$. The sample is considered as a plane capacitor and is described by a parallel resistor-capacitor circuit model. By applying an AC voltage across the two opposite sides of the plane samples, the conductance $(G)$ and capacitance $(C)$ were measured, and the data were analyzed to extract the relative dielectric constant and dielectric loss, considering the appropriate geometric coefficient. All PANI/epoxy resin composite samples were polished using a LOGITECH PM4 instrument (Logitech, Glasgow, UK)

\section{RESULTS AND DISCUSSION}

\section{Spectroscopy analysis}

The chemical structure and optical properties of the PANI-doped BSA and PANI composites were characterized by FTIR, Raman and UVVis-NIR spectroscopy. Figures 1a and b show the FTIR spectra, which are in agreement with previously reported results. ${ }^{9}$ The peaks at 1560 $1660 \mathrm{~cm}^{-1}$ and $1446 \mathrm{~cm}^{-1}$ are attributed to $\mathrm{C}=\mathrm{C}$ stretching vibrations of the quinoid and benzenoid rings, respectively. The $\mathrm{C}-\mathrm{N}$ stretching vibration is located at $1251 \mathrm{~cm}^{-1}$. The aromatic $\mathrm{C}-\mathrm{H}$ in-plane bending modes are usually observed at $1185 \mathrm{~cm}^{-1}$, the out-of-plane deformation of $\mathrm{C}-\mathrm{H}$ of a di-substituted benzene ring was located at $880 \mathrm{~cm}^{-1}$, and the vibration of $\mathrm{C}-\mathrm{H}$ was located at $3017-3053 \mathrm{~cm}^{-1} .{ }^{10}$ The absorption at $3404-3440 \mathrm{~cm}^{-1}$ is due to the $\mathrm{N}-\mathrm{H}$ stretching vibration. The peaks at $1000-1035 \mathrm{~cm}^{-1}$ and $750 \mathrm{~cm}^{-1}$ are related to the $\mathrm{S}=\mathrm{O}$ and S-O stretching vibrations of the sulfonate groups attached to the aromatic rings, indicating the doping state of the prepared PANIBSA. ${ }^{11}$ For the epoxy resin, we found bands at 3513 and $3059 \mathrm{~cm}^{-1}$ corresponding to the hydroxyl groups. The stretching vibration of $\mathrm{C}-\mathrm{H}$ and $\mathrm{CH}_{2}$ is located at $2934-2864 \mathrm{~cm}^{-1}$. Peaks related to the aromatic ring appear at $1613-1510 \mathrm{~cm}^{-1}$, and the bands at 1250 and 

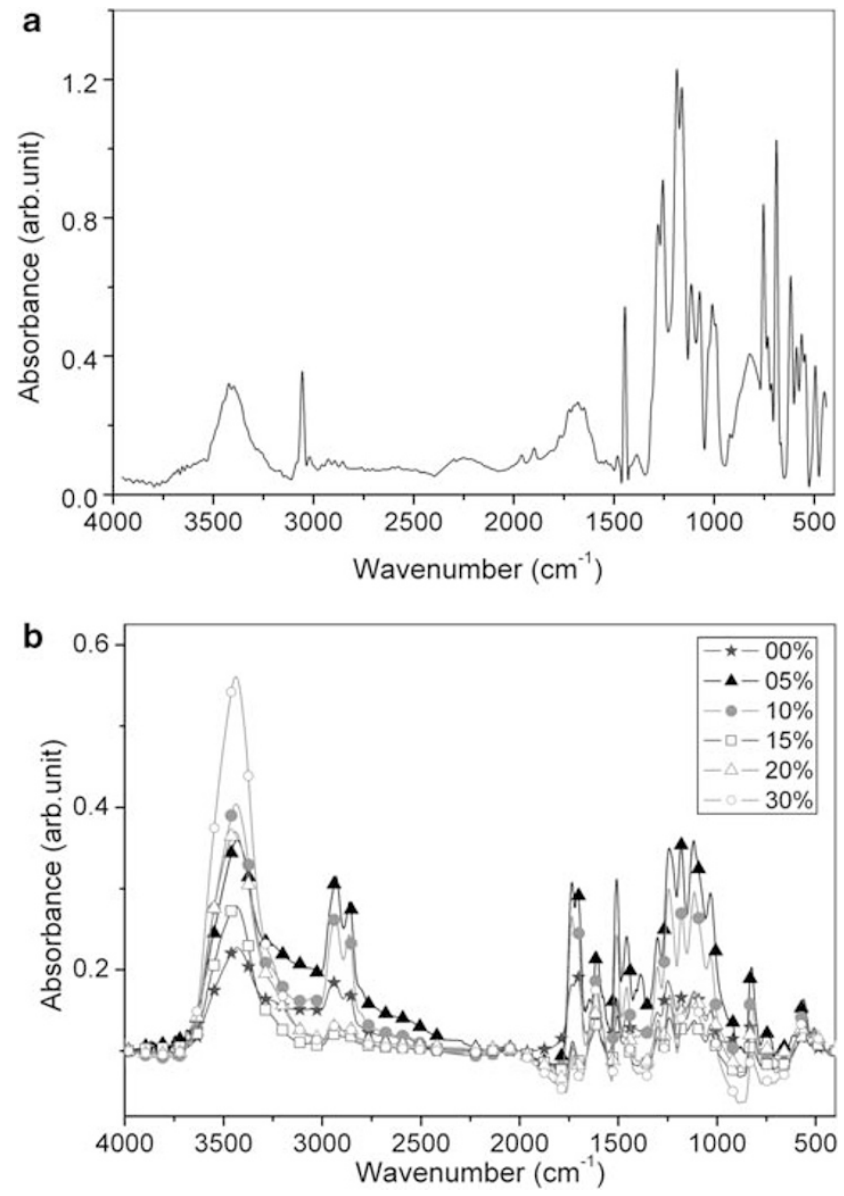

Figure 1 FTIR spectra of (a) PANI-doped BSA and (b) cured PANI composites.

$1180 \mathrm{~cm}^{-1}$ are attributed to the phenyl-C-phenyl and C-O-C. The esterification linking anhydride and epoxy groups are reflected at 1738 and $910 \mathrm{~cm}^{-1}$ in the composites. ${ }^{12,13}$ All the characteristic bands of PANI were manifested at $3430,1507,1592,1181$ and $828 \mathrm{~cm}^{-1}$ in the FTIR spectra of the PANI/epoxy composites, ${ }^{14}$ as reported in Figure $1 b$.

Figure 2 shows the UV-Vis-NIR spectrum of PANI-BSA. We noted two absorption peaks at about 338 and $655 \mathrm{~nm}$; the first band was assigned to the $\pi-\pi^{\star}$ transition in the benzenoid structure. ${ }^{15}$

The second band is because of exciton formation in the quinonoid rings arising from the transition of electrons between the HOMO orbital of the benzenoid ring and the LUMO orbital of the quinoid ring of the polymer. ${ }^{16,17}$ Another band around $896 \mathrm{~nm}$ could be assigned to the polaron transition of the polaron chain. ${ }^{18}$ An optical gap in the PANI-doped BSA was determined through spectroscopic analysis by applying the Pankove relation, $\alpha(h v)=A(h v-E g)^{1 / 2} \cdot{ }^{19}$ By extrapolating the curves to the energy $(h v)$ axis, the value was found to be $1.18 \mathrm{eV}$, which corresponds to a semiconductor energy gap.

The Raman signatures of the molecular structure of PANI-doped BSA powders and PANI/epoxy resin composite films deposited on silicon sheets are shown in Figures $3 \mathrm{a}$ and $\mathrm{b}$.

The $\mathrm{C}-\mathrm{C}$ and $\mathrm{C}=\mathrm{C}$ stretching of quinoid and benzoic units were observed at 1646 and $1598 \mathrm{~cm}^{-1}$, respectively. The band at $1509 \mathrm{~cm}^{-1}$ may be assigned to $\mathrm{N}-\mathrm{H}$ deformation vibrations associated with the quinonoid structure. ${ }^{20}$ The $\mathrm{C}-\mathrm{N}^{+\bullet}$ vibration of a delocalized polaronic structure was localized at $1342 \mathrm{~cm}^{-1} \cdot{ }^{21}$ In addition, the band located

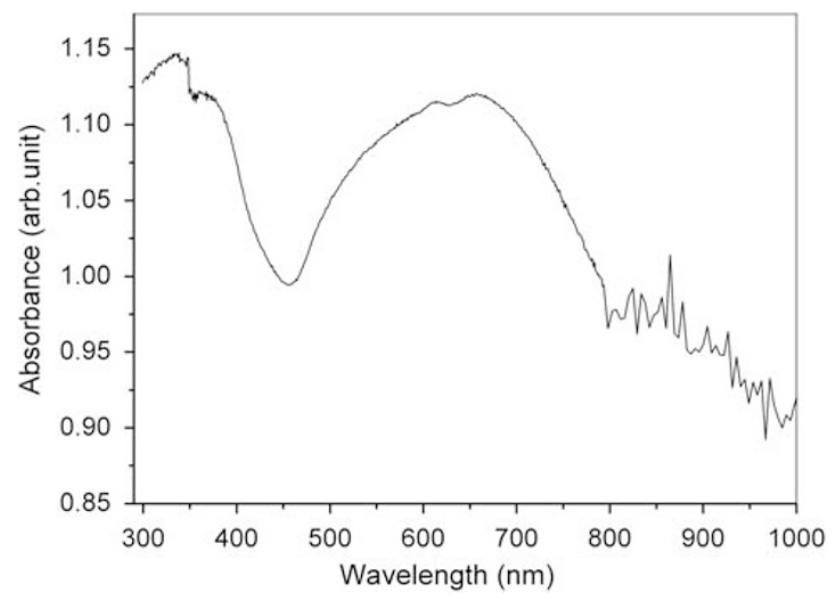

Figure 2 UV-Vis spectra of PANI-BSA.

at $1480 \mathrm{~cm}^{-1}$ may be assigned to stretching vibrations of $\mathrm{C}=\mathrm{N}$. The $\mathrm{C}-\mathrm{N}$ stretching vibrations of benzenoid, quinonoid and benzene ring deformations appear at the band of $(1247-1260) \mathrm{cm}^{-1} .{ }^{11}$ The band at $1170 \mathrm{~cm}^{-1}$ is characteristic of the $\mathrm{C}-\mathrm{H}$ bending vibration of the semiquinonoid rings. The deformation of the benzene ring $\mathrm{C}-\mathrm{N}-\mathrm{C}$ in the polaronic form is located at $860 \mathrm{~cm}^{-1}$, whereas the benzene ring deformation is around $811 \mathrm{~cm}^{-1}$. The band at $670-730 \mathrm{~cm}^{-1}$ characterizes the sulfate anion vibrations. The epoxy ring vibrations were located at $1246-1175 \mathrm{~cm}^{-1}$ and $814 \mathrm{~cm}^{-1}$ and were attributed respectively to the epoxy ring in-plane deformation and $\mathrm{CH}_{2}$ epoxy deformation. The esterification reaction involving the epoxy and hexahydrophtalic anhydride groups is located at $1380-1174 \mathrm{~cm}^{-1} .^{22}$

XRD was used to further probe the structures of the samples. XRD patterns of the PANI-doped BSA and PANI/epoxy resin composites are presented in Figures $4 \mathrm{a}$ and $\mathrm{b}$.

It is well known that crystalline or semicrystalline polymers are twophase systems containing ordered and disordered regions. PANI is a heterogeneous system consisting of a partly crystalline region and an amorphous region. In our case, PANI-doped BSA presented a signal that shows two main reflections located at $2 \theta=19.5$ and $2 \theta=25.4$. The first peak may be ascribed to the periodicity parallel to the polymer chain, whereas the second peak may be caused by the periodicity perpendicular to the polymer chain. ${ }^{18,23}$ These results are in agreement with those of Joo et al. and Fischer et al.,24-27 who observed reflections at the same angles for PANI powders. Thus, our results indicate an orthorhombic structure of the crystalline phases of PANIdoped BSA. All the composite samples with different ratios of PANI-BSA showed broad signal patterns with $2 \theta=(19.18-19.88)$ and $43^{\circ}$, with a shoulder around $24^{\circ}$. This broad X-ray structure suggests an amorphous character of the prepared composites. We noted a decrease in the intensity peaks with an increase in the PANI-BSA ratio in the composites and a shift in the $2 \theta$ value toward higher values.

\section{Morphology study}

The morphology of the PANI and composites was investigated using an SEM, and the results are shown in Figure 5. The micrograph was obtained on metallized films deposited on a silicon sheet using spin coating techniques.

In these images, we noted the existence of crystal, lamellar and linear forms $\sim 20 \mu \mathrm{m}$ in size, with flat and smooth surfaces, although the latter was the dominant morphology in the PANI-BSA micrographs, which has seldom been reported in the literature. This confirms that the doping agent used gives a pseudo-metallic char- 

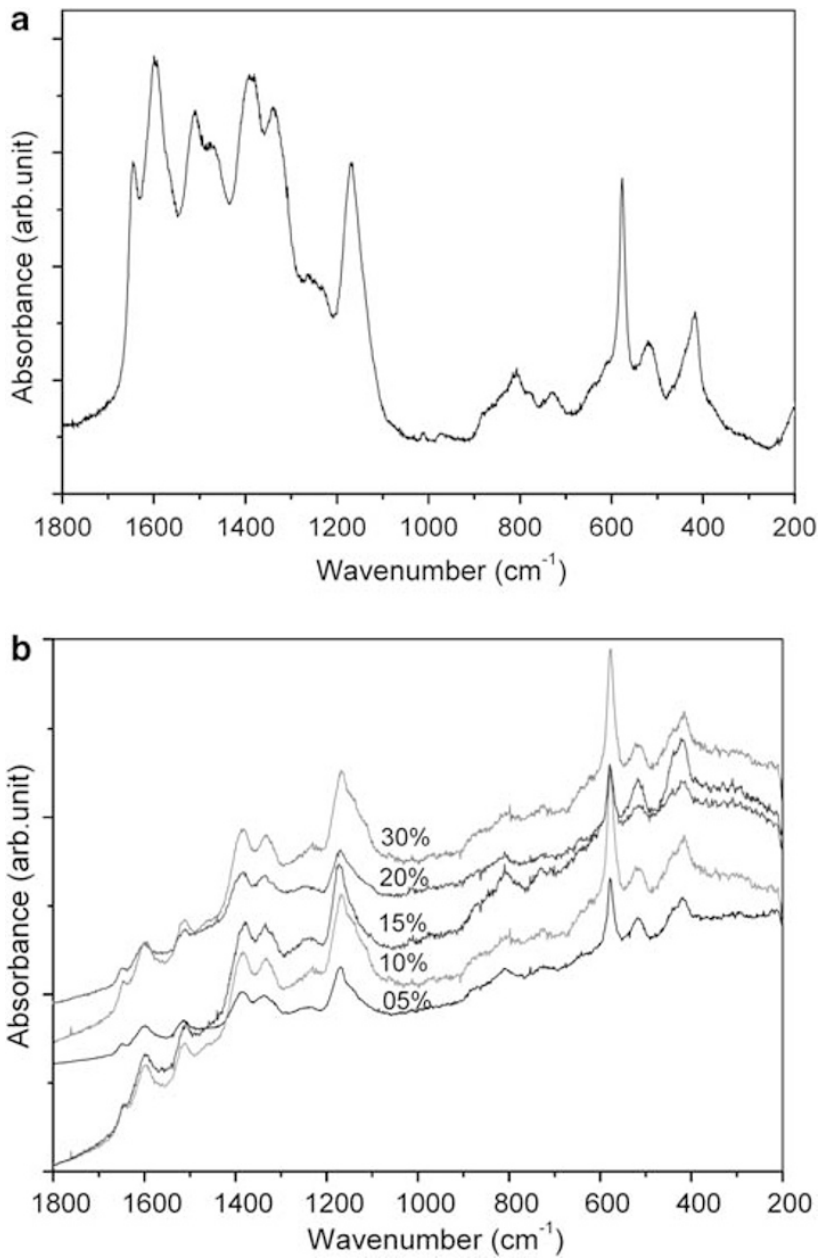

Figure 3 Raman spectra of (a) PANI-BSA and (b) cured PANI composites.

acteristic to the sample, as was confirmed by X-ray investigation. In the SEM micrographs of cured PANI/epoxy resin composite films, the white regions are PANI particles. For low ratios of PANI, the PANI particles were homogeneously and randomly dispersed in the epoxy matrix, indicating a homogeneous mixture of phases and good compatibility. However, when the weight content of PANI in the samples was above $15 \mathrm{wt} \%$, agglomerates of PANI in the matrix formed.

The topography of polished film surfaces of different samples deposited on glass, following the method of Avlyanov et al., ${ }^{28}$ was studied using AFM in tapping mode. The analyzed area ranged from 25 to $400 \mu \mathrm{m}^{2}$. The surface roughness results for the PANI and composite films are illustrated in Figure 6. The images are presented in three dimensions as originally recorded and have not been filtered or altered.

In the epoxy resin system without PANI, a homogeneous structure is observed; this may depict the developed crosslinked network of cured epoxy resin. However, the aim of the AFM study was to investigate the PANI-BSA topography and its distribution in the composites, not the structure of epoxy resin. This image is used as a reference for comparison with samples containing conductive salt. It can be seen in the PANI-doped BSA images that the films appear to be composed of tightly packed particles with nonuniform mountainous features and a broad base; this suggests that the film growth results
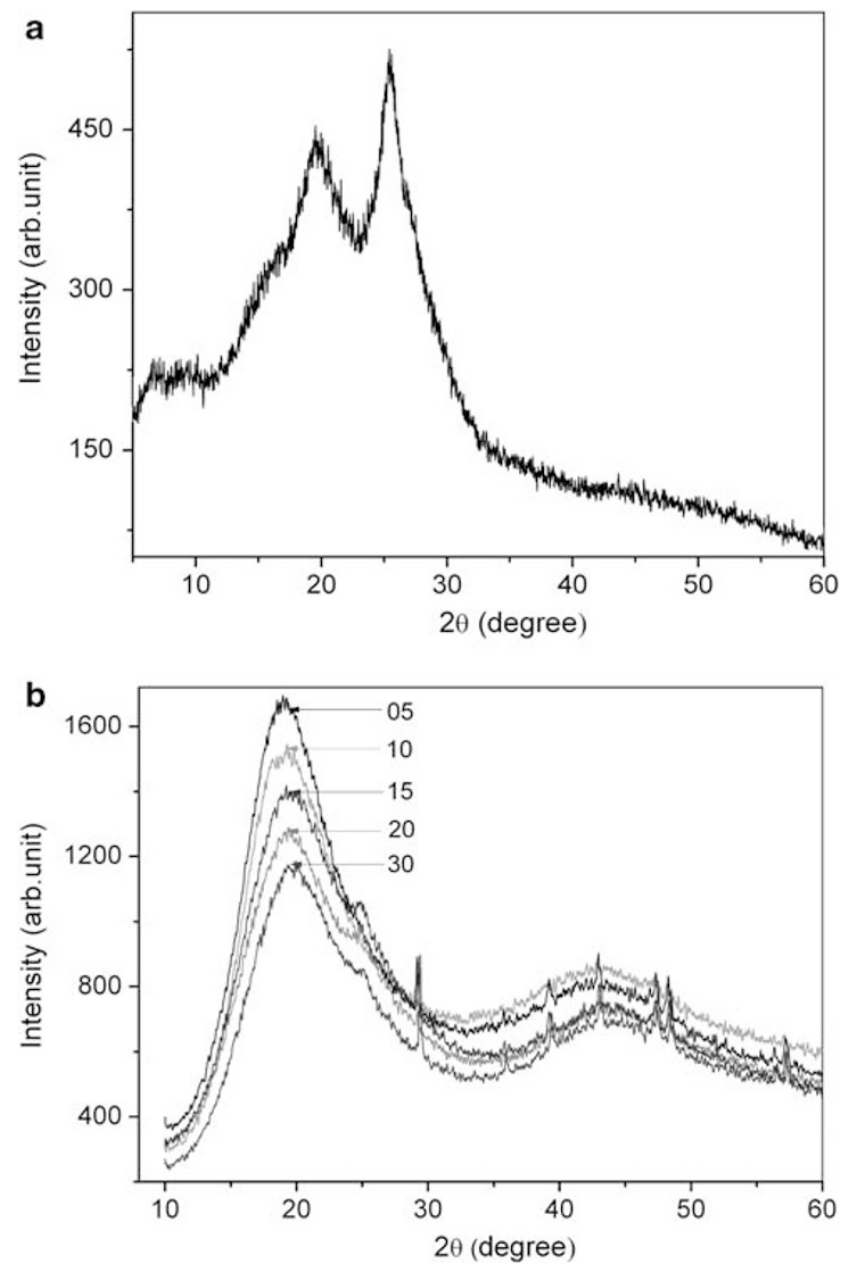

Figure 4 X-ray diffraction plot of (a) PANI-BSA and (b) PANI-BSA composites.

from the nucleation of particles on the surface where the lateral growth rate is high compared with the vertical growth or that it may be due to nonuniform doping of PANI. ${ }^{29}$ In the composite images, the PANI phases are clearly shown in the matrix. These images are in agreement with those of the SEM investigation.

\section{Electrical and dielectric properties}

The electrical conductivity of the PANI-doped BSA was measured at room temperature using a four-probe technique. The conductivity of each sample was measured three times at different positions of the sample, and the average of all the measurements was taken. The conductivity $(\sigma)$ can be given by the following relations: ${ }^{30}$

$$
\begin{aligned}
& \sigma=\ln 2 /(\pi \cdot R \cdot d) \\
& R=U / I
\end{aligned}
$$

where $I, U$ and $d$ are the set current (A), the measured voltage (V) and the thickness $(\mathrm{cm})$ of the sample, respectively.

Ideal ohmic behavior of the PANI was verified. The conductivity was found to be in the range of $8-10 \mathrm{~S} \mathrm{~m}^{-1}$. This value may be ascribed to low levels of protonation of the PANI chains and the formation of a semicrystalline phase, which is in concordance with the XRD results. The DC conductivity of the composite containing 30\% (wt $\%$ ) of PANI-doped BSA is in the order of $6.7 \times 10^{-3} \mathrm{~S} \mathrm{~m}^{-1}$, whereas 

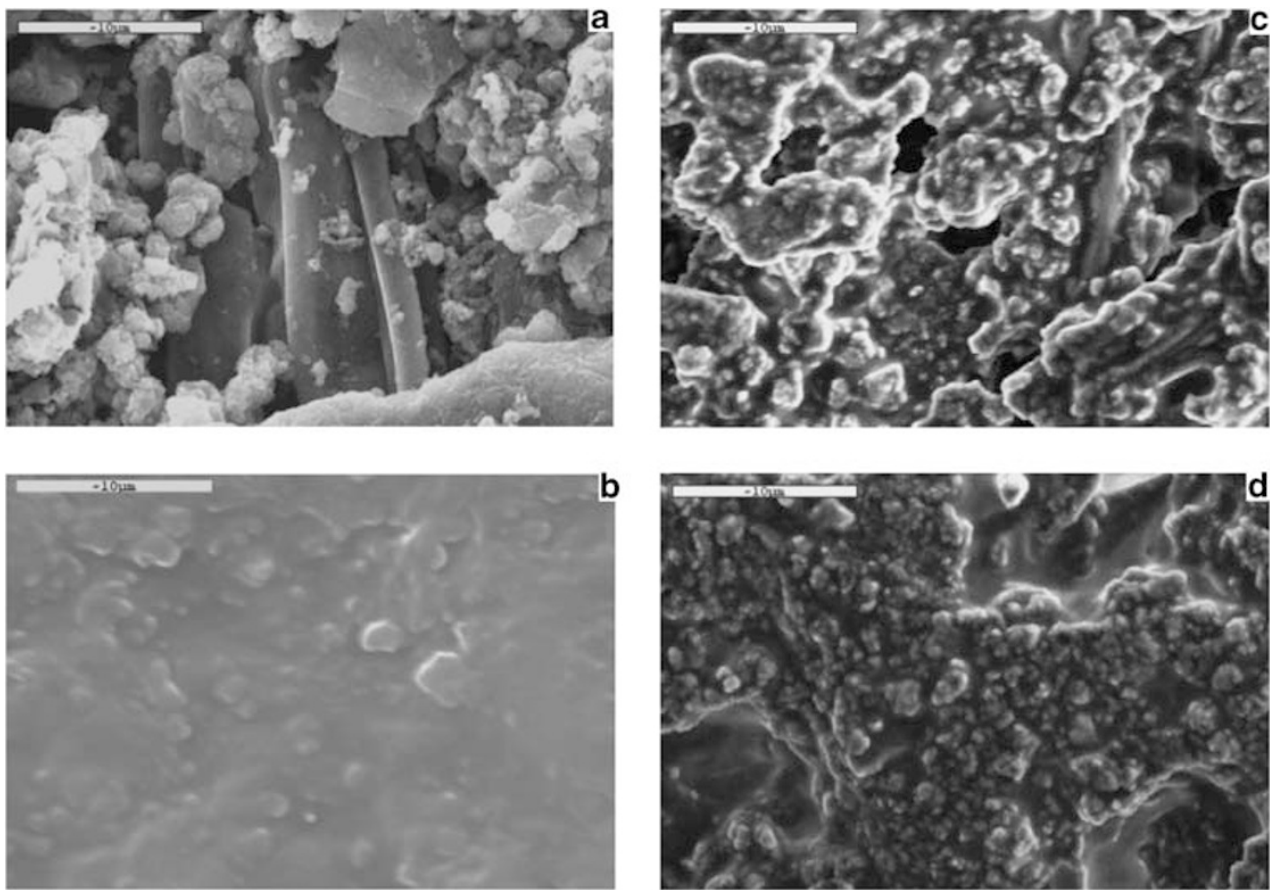

Figure 5 SEM micrographs of (a) PANI-BSA and PANI/epoxy resin composites with different amounts of PANI: (b) 5\%, (c) 15\% and (d) $30 \%$.

the conductivities of the other composites, which have lower contents of PANI, are lower than this range.

The current-voltage characteristics of the conducting PANI-doped BSA were measured at room temperature on samples with gold contacts deposited on both sides. The current-voltage characteristic variation with respect to the time between two measurements and the current (measured at $5 \mathrm{~V}$ ) dependence on this time are shown in Figures $7 \mathrm{a}$ and $\mathrm{b}$, respectively.

We observed that the current-voltage characteristics of PANI are completely symmetrical with respect to the polarity of the applied voltage and that they show nonohmic variations. This nonlinear increase in current with applied voltage is related to the conduction mechanisms of PANI. Indeed, the current is not only carried by free carriers (electrons and holes) as in semiconductors but also by the formation of polarons and bipolarons. As the applied voltage is increased, the formation of polarons and bipolarons increases rapidly, contributing to higher values of current through the sample. In addition, the current increases when the time between two measurements is increased. This may be explained by the presence of defects and the heterogeneous system of PANI with a crystalline (ordered) region dispersed in an amorphous (disordered) region. The conduction in the metallic region occurs by the hopping of charge carriers through the polaron structure that is formed after the protonation of PANI by BSA. However, the crystals are surrounded by an amorphous low-conductivity region consisting of disordered or folded chains; as a result, the overall conductivity of the PANI depends on bridges among the conductive regions. These results are in agreement with the SEM, AFM and XRD characterizations and with the findings described in the literature. 7,31

To study the dielectric properties, a silver paste contact was applied on both sides of the samples. Measurements of capacitance ( $C$, in Farads) and conductance ( $G$, in Siemens) were carried out at room temperature using an Agilent 4291A impedance analyzer (Agilent Technologies) with the frequency $f$ ranging from $1 \mathrm{MHz}$ to $1 \mathrm{GHz}$. The dielectric parameters and conductivity were used to obtain more detailed information with regard to the microscopic structure of the composites. These values were calculated from the capacitance and conductance using the following equations: ${ }^{32-38}$

$$
\begin{aligned}
& \varepsilon^{\prime}=C_{\mathrm{p}(\text { material })} / C_{0}, \varepsilon^{\prime \prime}=G_{(\text {material })} \cdot d / \omega \varepsilon_{0} \cdot A, \\
& \varepsilon^{*}=\varepsilon^{\prime}-\mathrm{i} \varepsilon^{\prime \prime}, \\
& \tan \delta=\varepsilon^{\prime \prime} / \varepsilon^{\prime}, \\
& \begin{aligned}
C_{0}=\varepsilon_{0} \cdot \mathrm{A} / \mathrm{d}, \\
\sigma_{\mathrm{AC}}^{*}(\omega)=\sigma^{\prime}+\mathrm{i} \sigma^{\prime}=\mathrm{i} \varepsilon_{0} \omega \varepsilon^{*}(\omega)=\mathrm{i} \varepsilon_{0} \omega\left(\varepsilon^{\prime}-\mathrm{i} \varepsilon^{\prime \prime}\right) \\
\quad=\varepsilon_{0} \cdot \omega \cdot \varepsilon^{\prime \prime}+\mathrm{i} \varepsilon_{0} \omega \varepsilon^{\prime},
\end{aligned} \\
& \sigma_{\mathrm{AC}}(\omega)=\omega \cdot C \cdot \tan \delta \cdot(\mathrm{d} / \mathrm{A})=\omega \cdot \varepsilon_{0} \cdot \varepsilon^{\prime \prime} .
\end{aligned}
$$

where $\varepsilon^{\prime}$ and $\varepsilon^{\prime \prime}$ are the real and imaginary parts of the complex dielectric constant $\varepsilon^{*}$. The real part measures the alignment of the dipoles, and the imaginary part represents the energy required to align the dipoles and move the ions. Tan $\delta$ is the dissipation factor, and $\delta$ is the phase angle. $C_{0}$ is the geometrical capacitance of a vacuum with the same dimensions as that of the sample. A and $\mathrm{d}$ are the area and thickness, respectively, of the sample. $C_{\mathrm{p}}$ is the capacitance, $\varepsilon_{0}=8.854 \times 10^{-12} \mathrm{~F} \mathrm{~m}^{-1}$ is the permittivity of free space, and $\omega=2 \pi f$ is the angular frequency. The real part of the complex AC conductivity $\sigma_{\mathrm{AC}}=\omega \cdot \varepsilon_{0} \cdot \varepsilon^{\prime \prime}$, which is equivalent to the dielectric conductivity, was exploited for all samples.

The dielectric behavior illustrated in Figures $8 \mathrm{a}$ and $\mathrm{b}$ shows the variation of the real $\left(\varepsilon^{\prime}\right)$ and imaginary part $\left(\varepsilon^{\prime \prime}\right)$ of the complex permittivity of the composites as a function of frequency.

In all cases, it was found that by adding PANI powder to the matrix, the dielectric constant increased to a high value (15.5-26) for frequencies in the vicinity of $25 \mathrm{MHz}$ and decreased slightly as the frequency increased up to $180 \mathrm{MHz}$; beyond this point, it remained stable. In addition, the imaginary part at $1 \mathrm{GHz}$ increased from 0.2 to 
a
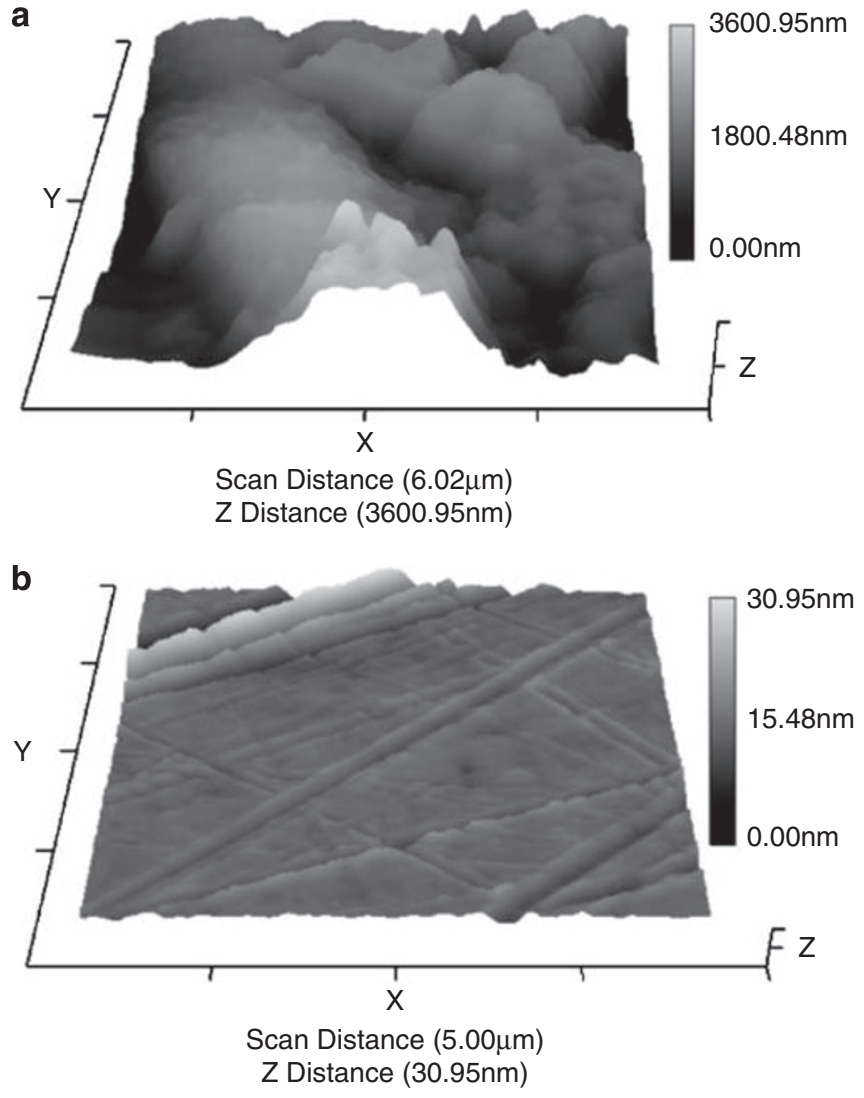

C

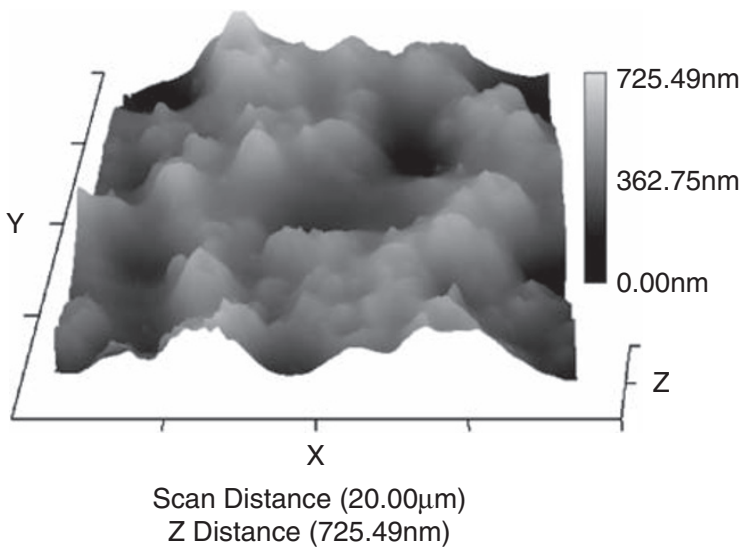

Figure 6 Three-dimensional AFM images of (a) PANI-BSA, (b) cured epoxy resin and (c) PANI/epoxy resin composites at 15\%.

1.7 for $20 \%$ PANI. This may be due to the fact that, at low frequencies, the dipoles have sufficient time to align with the field before it changes direction and the dielectric constant is high, but at high frequencies, the dipoles do not have time to align before the field changes direction and the dielectric constant is lower. At intermediate frequencies, the dipoles move but do not complete their alignment before the field changes direction. It is believed that a decrease in the dipolar polarization of the matrix and an accumulation of charges at the interface between the PANI particles and the epoxy resin result in a large-scale field distortion; this is also a result of variations in the distribution of PANI in the matrix, as revealed by SEM and AFM. From $160 \mathrm{MHz}$ to $1 \mathrm{GHz}$, the variations of permittivity are very small and almost constant.
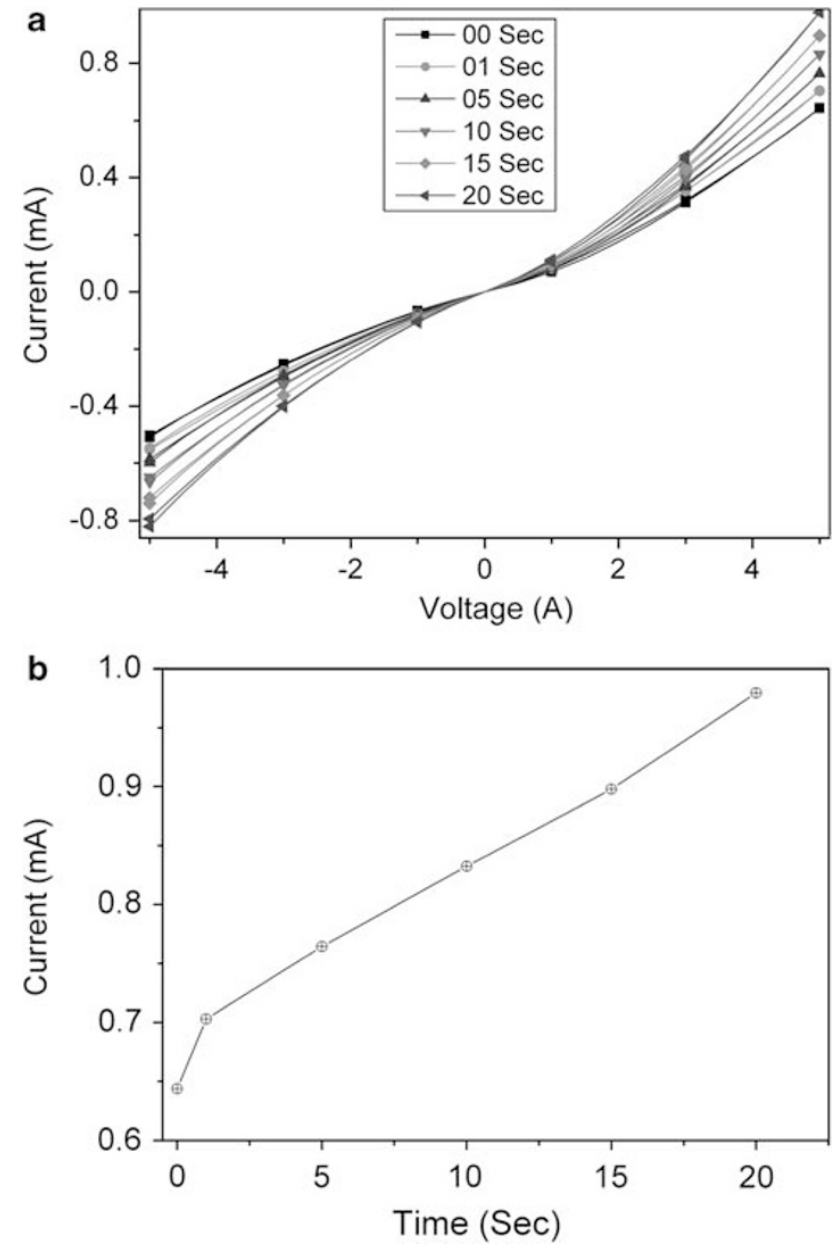

Figure 7 Current-voltage characteristics of PANI-BSA films with respect to the time $\Delta t$ between two measurements (a) and the current (measured at $5 \mathrm{~V}$ ) dependence on $\Delta t$ (b).

The frequency dependence of the loss, $\tan \delta$, and the AC conductivity of the PANI/epoxy resin composites is presented in Figures $9 \mathrm{a}$ and $\mathrm{b}$.

It is shown that $\tan \delta$ has a high value at low frequencies ranging between 0.5 and 2.5 at $7 \mathrm{MHz}$ and then decreases with increasing frequency, reaching a value of 0.05 at $20 \mathrm{MHz}$. It then increases slowly with PANI percentage and is nearly constant at high frequencies. The observed behavior of dielectric loss is in accordance with the conductivity and dielectric constant results of the reported composites. Figure $9 \mathrm{~b}$ shows that the frequency dependence of the conductivity is strongly related to the character of the conduction phenomenon and charge transport in these composites. The AC conductivity sums over all the dissipative effects of the material. It may represent an actual conductivity caused by migrating charge carriers, and it may also refer to lost energy associated with the dispersion of $\varepsilon^{\prime}{ }^{39}$ The AC conductivity, $\sigma_{\mathrm{AC}}$, must be distinguished from its DC value, $\sigma_{\mathrm{DC}}$, because it may include permanent dipole orientation losses, as well as frequency-dependent space charge polarization-controlled carrier migration processes, which do not arise under DC conditions. It is shown that for all of these composites at low frequencies, the conductivity is almost constant, showing the AC conductivity characteristic of disordered materials. Up to the value of $21.91 \mathrm{MHz}$, which may be a critical frequency $\left(f_{\mathrm{c}}\right)$, the conductivity increases gradually with increasing frequency (relaxation region). ${ }^{40}$ This amplification is 

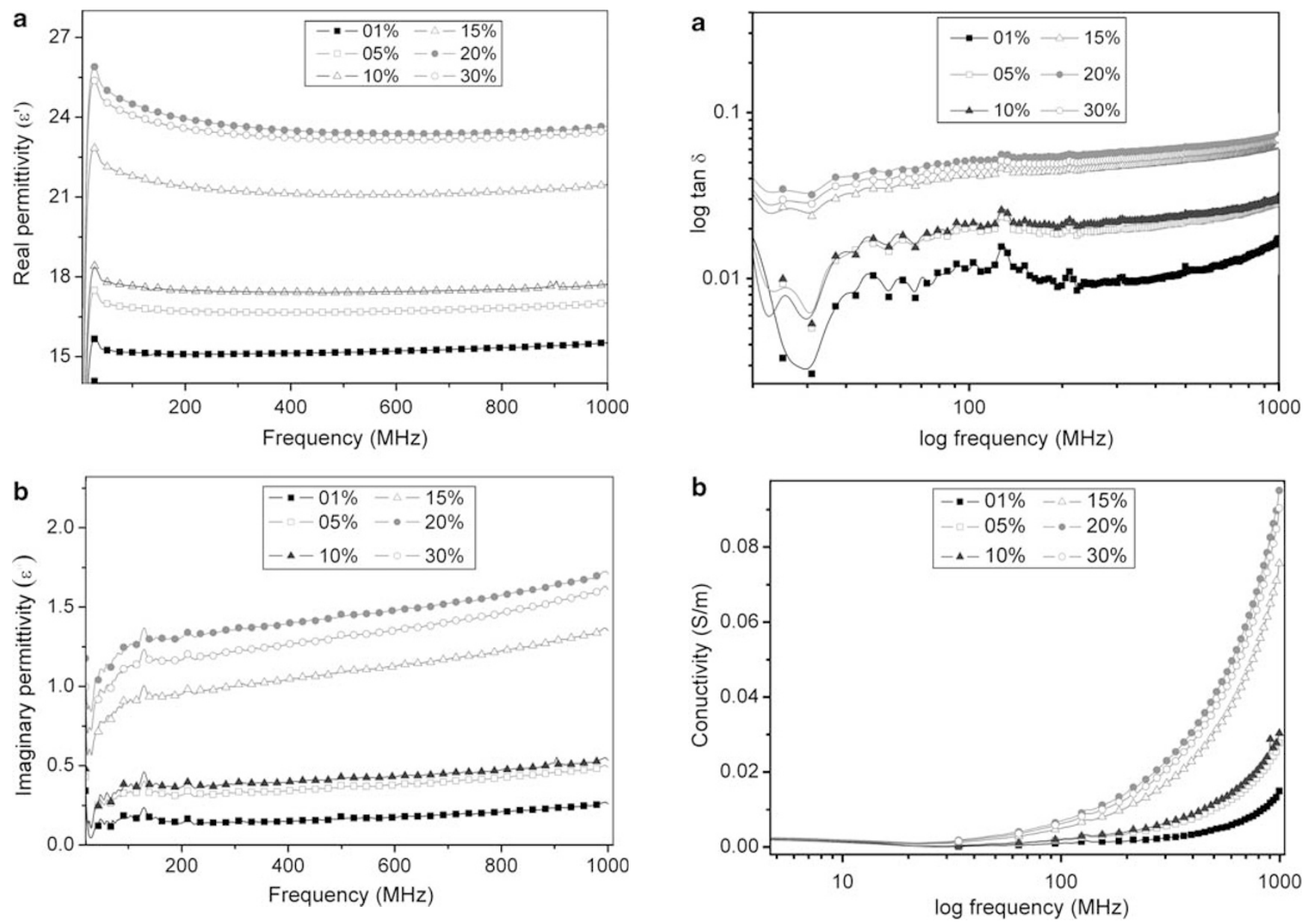

Figure 8 The composite frequency dependence of (a) the real permittivity and (b) imaginary permittivity.

greater for the composites with higher PANI contents. This phenomenon can be explained by the power law equation: $\sigma_{\mathrm{AC}}(\omega) \sim \mathrm{A} \omega^{z}$, which describes the pseudo-linear dependence of AC conductivity on the frequency for various amorphous materials, where $\mathrm{A}$ is a constant dependent on temperature and $(z \leqslant 1)$ is a criterion sensitive to the type of conduction-relaxation mechanism dominant in amorphous materials. ${ }^{41}$ The increase in the AC conductivity with PANI loading may result from two causes. First, this may be due to the increased charge carrier concentration and the easier formation of a conducting network through better interparticle contact among PANI particles dispersed in the matrix polymer. Second, it may arise from the differences in the dielectric constant and conductivity of the PANI and epoxy resin. The frequency dependence of the AC conductivity is considered to be a result of interface charge polarization or the Maxwell-Wagner-Sillars effect and intrinsic electric dipole polarization. ${ }^{42}$ This phenomenon is observed in heterogeneous system due to the accumulation of mobile charges at the interfaces and the formation of large dipoles in clusters. It has been found that the dielectric constant and conductivity increase with increasing PANI concentration in the matrix. The dependencies of the dielectric constant and AC conductivity up to $1 \mathrm{GHz}$ for the PANI/epoxy resin composites are shown in Figure 10 and recapitulated in Table 1. By adding $20 \mathrm{wt} \%$ of PANI-doped BSA, the dielectric constant is increased from 15.53 to 23.66, and the loss tangent is lower than 0.073.

The addition of PANI in the matrix and the elimination of agglomerates surrounded by an insulating matrix result in the forma-

Figure 9 The PANI/epoxy resin composite frequency dependence of (a) the loss, $\tan \delta$, and (b) the AC conductivity, $\sigma(\omega)$.

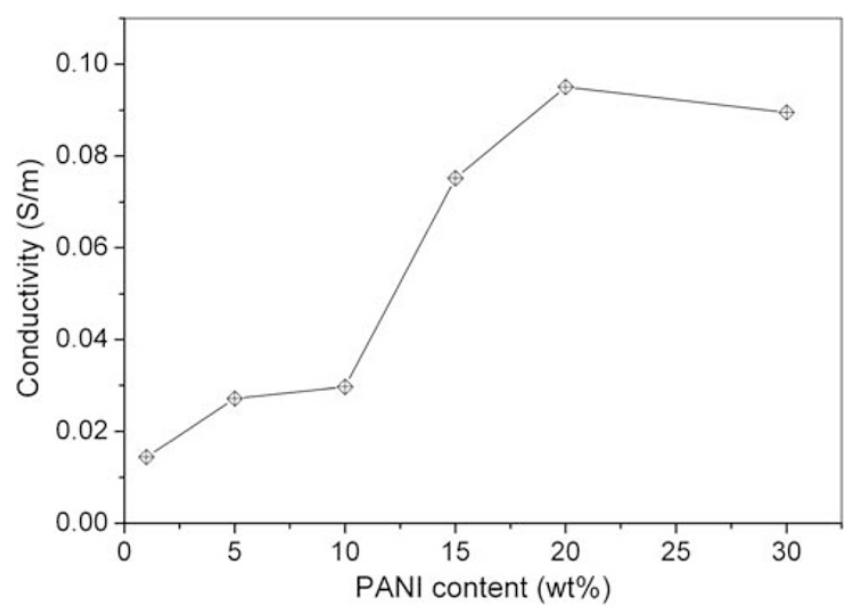

Figure 10 Evolution of AC conductivity with PANI contents in composites at $1 \mathrm{GHz}$.

tion of a fine network, which allows charge transfer to occur easily through the well-ordered polymer, leading to enhanced dielectric properties of the composites.

An increase in the PANI content in the composites increases the dipole density by ordering the arrangement of chains in the disordered 
Table 1 AC conductivity, the loss tan and real and imaginary part of complex permittivity at $1 \mathrm{GHz}$ for different PANI/epoxy resin composites

\begin{tabular}{lcccc}
\hline PANI (\%) & $\varepsilon^{\prime}$ & $\varepsilon^{\prime \prime}$ & $\tan \delta$ & $\sigma(\omega) \times 10^{-2}\left(\mathrm{Sm}^{-1}\right)$ \\
\hline 1 & 15.530 & 0.260 & 0.0167 & 1.44 \\
5 & 17.310 & 0.489 & 0.0287 & 2.72 \\
10 & 17.720 & 0.535 & 0.0310 & 2.97 \\
15 & 21.460 & 1.353 & 0.0630 & 7.52 \\
20 & 23.663 & 1.711 & 0.0730 & 9.52 \\
30 & 23.496 & 1.611 & 0.0687 & 8.95
\end{tabular}

Abbreviations: $\varepsilon^{\prime}$ and $\varepsilon^{\prime \prime}$, the real and imaginary parts of the complex dielectric constant $\varepsilon^{*}$; PANI, polyaniline; $\tan \delta$, dissipation factor; $\sigma(\omega)$, the AC conductivity.
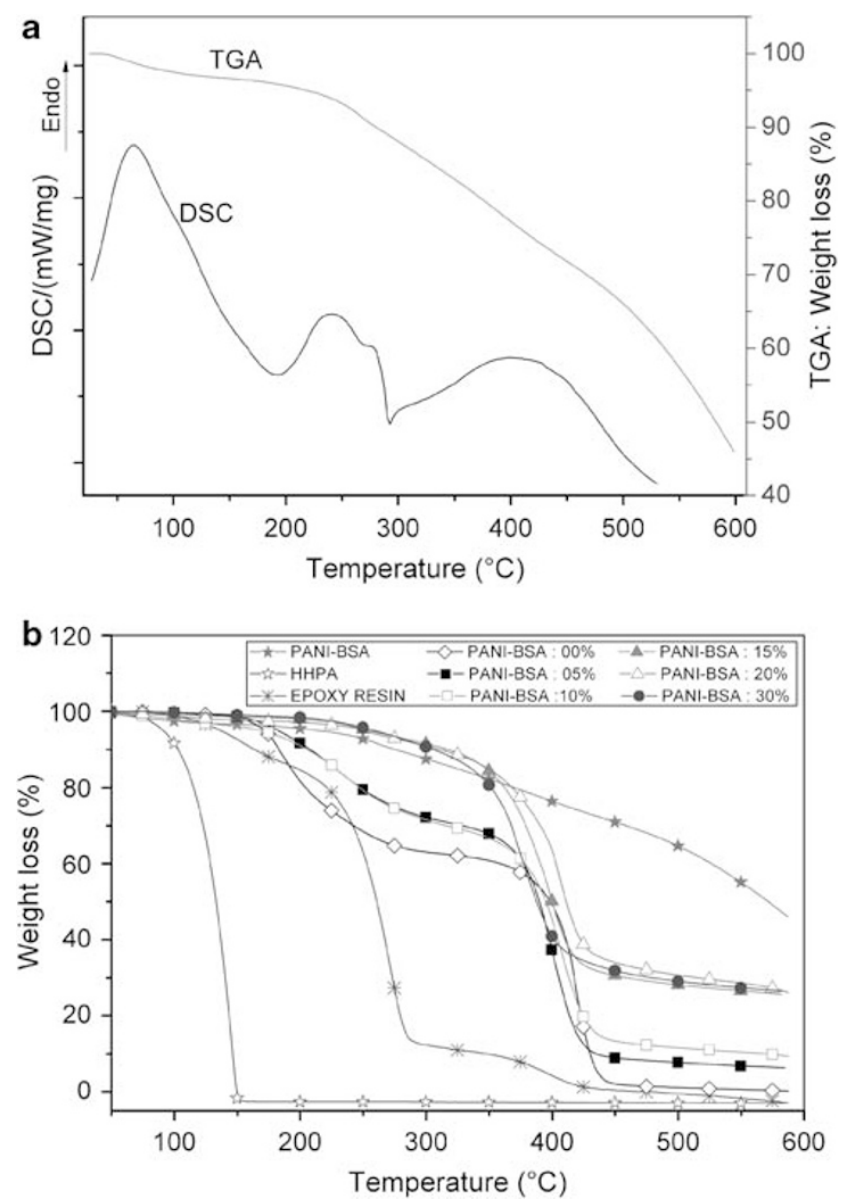

Figure 11 (a) DSC and TGA thermograms of PANI-BSA and (b) TGA curves of cured PANI/epoxy resin composites.

polymer. With the application of an external electric field, strong dipole-dipole interactions between the PANI and epoxy resin allow the charges to hop from one dipole to another throughout the polymer composite matrix; as the amount of PANI increases, the dipole density increases along with the mobility of the dipoles, which in turn depends on the mobility of the polymer chains to which the dipoles are attached. As a result, an increase in the values of the permittivity and dielectric loss factor is observed with increasing PANI content in the composites. ${ }^{43}$ As the concentration of PANI-doped BSA in the composite increased to $20 \mathrm{wt} \%$ of PANI, the AC conductivity reached $9.50 \times 10^{-2} \mathrm{~S} \mathrm{~m}^{-1}$. These results reveal that the addition of
PANI in composites increases the conductivity of PANI-epoxy resin composites to a range that is suitable for antistatic and RAM applications. ${ }^{44-46}$

\section{Thermal analysis}

PANI-doped BSA powders and cured PANI/epoxy resin composites were characterized by TGA under a nitrogen purge in the temperature range of $25-600^{\circ} \mathrm{C}$. Figures $11 \mathrm{a}$ and b illustrate the weight loss ( $\mathrm{wt} \%$ ) of all of the PANI samples as a function of temperature. Three steps of weight loss occurred in the TGA curves of the PANI samples, in agreement with the results in the literature. ${ }^{47}$ The first step of a small weight loss, starting at $30-170{ }^{\circ} \mathrm{C}$, was apparently caused by the loss of strongly and slightly absorbed molecules of water and loss of oligomers. The second step of weight loss, occurring between 170 and $390^{\circ} \mathrm{C}$, could be attributed to the evaporation and degradation of BSA and the oxidation process of the PANI structure. These observations were confirmed on the first-run thermograms of PANI-doped BSA obtained by differential scanning calorimetry measurements, as shown in Figure 11b, which shows an endotherm between 30 and $175^{\circ} \mathrm{C}$ corresponding to the small weight loss of water and oligomers observed in the TGA and a double endothermic peak corresponding to the doping agent loss as revealed by TGA analysis. ${ }^{26}$ The weight loss corresponding to the third step $\left(390-600^{\circ} \mathrm{C}\right)$ is mainly due to thermal decomposition of the composites and degradation of PANI into chemical forms.

It is shown that the decomposition temperatures of epoxy resin and the curing agent are 267.5 and $150{ }^{\circ} \mathrm{C}$, respectively. Furthermore, all the composites present a sharp weight loss above $360^{\circ} \mathrm{C}$, corresponding to the degradation of the composites. In addition, the residual mass was proportional to the PANI content. We found that the cured PANI/epoxy resin composites have increased stability with increased PANI loading at high temperatures. ${ }^{48}$ An interesting observation is that $>60 \mathrm{wt} \%$ of the PANI-doped BSA is stable up to $600{ }^{\circ} \mathrm{C}$; this may be explained by the slower loss of the doping agent from inside the polymer chains, because of the molecular structure based on $(-\mathrm{N}-)$, $(-\mathrm{N}=)$ and the heteroatom incorporated between phenyl rings on the chain length. Moreover, the interactions among the chains increase the rigidity and stability of the material. These results are in agreement with the literature. ${ }^{49-51}$

\section{CONCLUSION}

In this paper, conducting PANI-doped BSA with moderate protonation was successfully synthesized by conventional oxidative polymerization. A spectroscopy study confirmed its chemical structure. XRD patterns demonstrated the semicrystallinity of the PANI-doped BSA. The electrical behavior shows disorder and the defects of the PANI. Conducting PANI/epoxy resin composites with different amounts, up to $20 \mathrm{wt} \%$, of PANI were investigated and were found to have conductivities below $9 \times 10^{-2} \mathrm{~S} \mathrm{~m}^{-1}$. The homogenous dispersion of PANI in the epoxy resin was revealed by AFM and SEM. The dielectric constant was high at low frequencies and nearly stable at high frequencies. The AC conductivity obeys the power law well above the critical frequency for each composite. The increase in AC conductivity with an increase in the PANI content may be attributed to the intrinsic electric dipole polarization and to conformational changes in PANI. It was found that the PANI-doped BSA is thermally stable up to $600^{\circ} \mathrm{C}$ and that the stability of the PANI/epoxy resin increases with increasing PANI filler in the matrix.

The dielectric constant and conductivity values of the prepared composites may prove useful in electromagnetic shielding or antistatic coating applications. 


\section{ACKNOWLEDGEMENTS}

We thank all the researchers at LMOPS and SUPELEC and Jean-Luc Peirrot at the Physics Laboratory of Dense Media, Institute of Physics and Electronics of Metz, France, for experimental assistance. Franck Ducos, Nouari Chaoui (Department of Sciences and Materials Engineering, IUT, Forbach, France) and Denis Bouscand (ENSAM, Metz, France) are acknowledged for their discussions and technical help.

1 Esma, S., Özlem, Y., Ram, M. K. \& Matt, A. in The New Frontiers of Organic and Composite Nanotechnology, (eds. Victor E., Manoj K. R. and Ozlem Y.), Ch 4 and 9 (Elsevier, Oxford, UK, 2008).

2 Marie, A. Handbook of Conducting Polymers, 2nd edn, 921-944 (eds. T. A. Skotheim, R. L. Elsenbaumer, J. R. Reynold (Marcel Dekker, INC, New York, 1998).

3 Patidar, D., Jain, N., Saxena, N. S., Sharma, K. \& Sharma, T. P. Electrical properties of CdS/polyaniline heterojunction. Braz. J. Phys. 36, 1210-1212 (2006).

4 Poopathy, K. Curable electrically conductive resin with polyaniline fillers. Polymer $\mathbf{3 4}$, 2907-2908 (1993).

5 Tiezhu, F., Jia, L., Jing, W. \& Hui, N. Cure kinetics and conductivity of rigid rod epoxy with polyaniline as a curing agent. Polymer Composites 30, 1394-1400 (2009).

6 Jiongxin, L., Moon, K. S., Kim, B. K. \& Wong, C. P. High dielectric constant polyaniline/ epoxy composites via in situ polymerization for embedded capacitor applications. Polymer 48, 1510-1516 (2007).

7 Sambhu, B., Dipak, K., Singha, N. K. \& Lee, J. H. Progress in preparation, processing and applications of polyaniline. Prog. Polym. Sci. 34, 783-810 (2009).

8 Akatsuka, M., Takezawa, Y. \& Amagi, S. Influences of inorganic fillers on curing reactions of epoxy with a boron trifluoride amine complex. Polymer 42, 3003-3007 (2001).

9 Jeevananda, T., Palaniappan, S. \& Siddaramaiah Spectral and thermal studies on polyaniline-epoxy novolac resin composite materials. J. Appl. Polym. Sci. 74, 3507-3512 (1999).

10 Miroslava, T., Pavel, M., Jitka, B., Andrea, K., Jan, P. \& Jaroslav, S. Structural and conductivity changes during the pyrolysis of polyaniline base. Polym. Degrad. Stab. 91, 114-121 (2006).

11 Ivana, S., Miroslava, T. \& Jaroslav, S. Thermal degradation of polyaniline films prepared in solutions of strong and weak acids and in water. FTIR and Raman spectroscopic studies. Polym. Degrad. Stab. 93, 2147-2157 (2008).

12 Dean, K., Cook, W. D., Burchill, P. \& Zipper, M. Curing behaviour of IPNs formed from model VERs and epoxy systems: Part II. Imidazole-cured epoxy. Polymer 42, 3589-3601 (2001).

13 Yun, Z., Kim, C., Xiaolin, J., Ping, W. \& Pingkai, J. Study on the curing reaction, dielectric and thermal performances of epoxy impregnating resin with reactive silicon compounds as new diluents. J. Appl. Polym. Sci. 107, 3127-3136 (2008).

14 Koul, S., Chandra, R. \& Dhawan, S. K. Conducting polyaniline composite for ESD and EMI at $101 \mathrm{GHz}$. Polymer 41, 9305-9310 (2000).

15 De Albuquerque, J. E., Mattoso, L. H. C., Faria, R. M., Masters, J. G. \& MacDiarmid, A. G. Study of the interconversion of polyaniline oxidation states by optical absorption spectroscopy. Synth. Met. 146, 1-10 (2004).

16 Albuquerque, J. E., Mattoso, L. H. C., Balogh, D. T., Faria, R. M., Masters, J. G. \& MacDiarmid, A. G. A simple method to estimate the oxidation state of polyanilines. Synth. Met. 113, 19-22 (2000).

17 Phang, S.- W., Tetsuo, H., Abdullah, M. H. \& Noriyuki, K. Applications of polyaniline doubly doped with p-toluene sulphonic acidand dichloroacetic acid as microwave absorbing and shielding materials. Mater. Chem. Phys. 104, 327-335 (2007).

18 Junsheng, W., Jixiao, W., Zhen, Y., Zhi, W., Fengbao, Z. \& Shichang, W. A novel strategy for the synthesis of polyaniline nanostructures with controlled morphology. React. Funct. Polym. 68, 1435-1440 (2008).

19 Naar, N., Lamouri, S., Belaabed, B., Kouroughli, T. \& Gabouze, N. Influence of dibenzoyl tartaric acid on the electrical performances of the polyaniline. Polymer Journal 41, 1-5 (2009).

20 Jiaxin, Z., Chen, L. \& Gaoquan, S. Raman spectroscopic study on the structural changes of polyaniline during heating and cooling processes. J. Appl. Polym. Sci. 96, 732-739 (2005).

21 Mazeikiene, R., Niaura, G. \& Malinauskas, A. In situ Raman spectroelectrochemical study of electrocatalytic oxidation of ascorbate at polyaniline and sulfonated polyaniline-modified electrodes. Electrochimica Acta 51, 5761-5766 (2006).

22 Pellegrino, M., Mario, A., Giuseppe, R. \& Gennaro, S. A Study by Raman, near-infrared and dynamic-mechanical spectroscopies on the curing behaviour, molecular structure and viscoelastic properties of epoxy/anhydride networks. Polymer 48, 3703-3716 (2007).

23 Han, Y. G., Takafumi, K. \& Tohru, S. One-step reverse micelle polymerization of organic dispersible polyaniline nanoparticles. Synth. Met. 159, 123-131 (2009).
24 Joo, J., Chung, Y. C., Song, H. G., Baeck, J. S., Lee, W. P., Epstein, A. J., MacDiarmi, A. G., Jeong, S. K. \& Oh, E. J. Charge transport studies of doped polyanilines with various dopants and their mixtures. Synth. Met. 84, 739-740 (1997).

25 Fischer, J. E., Tang, X., Scherr, E. M., Cajipe, V. B. \& Macdiarmid, A. G. Polyaniline fibers and films: stretch-induced orientation and crystallization, morphology, and the nature of the amorphous phase. Synth. Met. 41, 661-664 (1991).

26 Zilberman, M., Titelman, G. I., Siegmann, A., Haba, Y., Narkis, M. \& Alperstein, D. Conductive blends of thermally dodecylbenzene sulfonic acid, doped polyaniline with thermoplastic polymers. J. Appl. Polym. Sci. 66, 243-253 (1997).

27 Jozefowicz, M. E., Epstein, A. J., Pouget, J.- P., Masters, J. G., Ray, A., Sun, Y., Tang, X. \& MacDiarmid, A. G. X-Ray structure of Polyanilines. Synth. Met. 41, 723-726 (1991).

28 Avlyanov, J. K., Josefowicz, J. Y. \& MacDiarmid, A. G. Atomic force microscopy surface morphology studies of in situ deposited polyaniline thin films. Synth. Met. 73, 205-208 (1995).

29 Tushar, J., Jhunu, C. \& Arun, K. N. Sulfonic acid doped thermoreversible polyaniline gels. 3. Structural investigations. Langmuir 18, 5720-5727 (2002).

30 Ting, C., Chaofang, D., Xiaogang, L. \& Jin, G. Thermal degradation mechanism of dodecylbenzene sulfonic acid- hydrochloric acid co-doped polyaniline. Polym. Degrad. 94, 1788-1794 (2009).

31 Sambhu, B. \& Dipak, K. Determination of crystal structure of polyaniline and substituted polyanilines through powder X-ray diffraction analysis. Polym. Test. 27, 851-857 (2008)

32 Kranbuehl, D. E., Delos, S. E. \& Jue, P. K. Dielectric properties of the polymerization of an aromatic polyimide. Polymer 27, 11-18 (1986).

33 Ravikiran, Y. T., Lagare, M. T., Sairam, M., Mallikarjuna, N. N., Sreedhar, B., Manohar, S., MacDiarmid, A. G. \& Aminabhavi, T. M. Synthesis, characterization and low frequency $\mathrm{AC}$ conduction of polyaniline/niobium pentoxide composites. Synth. Met. 156, 1139-1147 (2006).

34 Natsuko, N., Yu-Hsin, L., Anthony, J. B., Vivek, M. P. \& Chad, R. S. Dielectric properties of nylon 6/clay nanocomposites from on-line process monitoring and off-line measurements. Polymer 46, 720-7217 (2005).

35 Truong, V.- T. \& Ternan, J. G. Complex conductivity of a conducting polymer composite at microwave frequencies. Polymer 36, 905-909 (1995).

36 Navin, C. \& Deepak, J. Evaluation of a.c. conductivity behaviour of graphite filled polysulphide modified epoxy composites. Bull. Mater. Sci. 27, 227-233 (2004).

37 Psarras, G. C. Hopping conductivity in polymer matrix-metal particles composites. Composites. Part A, 37, 1545-1553 (2006).

38 Tataroglu, A., Yucedag, I. \& Altindal, S. Dielectric properties and ac electrical conductivity studies of MIS type Schottky diodes at high temperatures. Microelectronic Engineering 85, 1518-1523 (2008).

39 Chen, L. F., Ong, C. K., Neo, C. P., Varadan, V. V. \& Varadan, V. K. Microwave Electronics, Mesurements and Materials Characterization (John Wiley \& Sons, London, UK, 2004).

40 Michaela, P., Jarmila, V., Robert, M., Petr, S., Jaroslav, S. \& Otakar, Q. Effect of coating of graphite particles with polyaniline base on charge transport in epoxy-resin composites. J. Mater. Sci. 42, 4942-4946 (2007).

41 Saravanan, S., Joseph Mathai, C., Anantharaman, M. R., Venkatachalam, S. \& Prabhakaran, P. V. Investigations on the electrical and structural properties of polyaniline doped with camphor sulphonic acid. J. Phys. Chem. Solids 67, 1496-1501 (2006).

42 Arup, C. Polyaniline/silver nanocomposites. Dielectric properties and ethanol vapour sensitivity. Sens. Actuators B Chem. 138, 318-325 (2009).

43 Afzal, A. B., Akhtar, M. J., Nadeem, M. \& Hassan, M. M. Dielectric and impedance studies of DBSA doped polyaniline/PVC composites. Curr. Appl. Phys. 10, 601-606 (2010).

44 Sudha, J. D., Sivakala, S., Prasantha, R., Reena, V. L. \& Radhakrishnan, N. P. Development of electromagnetic shielding materials from the conductive blends of polyaniline and polyaniline-clay nanocomposite-EVA: preparation and properties. Compos. Sci. Technol. 69, 358-364 (2009).

45 Tsotra, P. \& Friedrich, K. Electrical and dielectric properties of epoxy resin/polyanilineDBSA blends. J. Mater. Sci. 40, 4415-4417 (2005).

46 Cristiane, R. M., Roselena, F., Mirabel, C. R. \& Marco, A. D. P. Microwave absorption properties of a conductive thermoplastic blend based on polyaniline. Polym. Bullet. 51, 321-326 (2004).

47 Mohammad, F. Stability of electrically conducting polymers, Vol. 8: Conducting Polymers. in Handbook of Advanced Electronic and Photonic Materials and Devices (ed. Nalwa, H.S.) (Academic Press, London, UK, 2001).

48 Lamouri, S. \& Zeghina, S. Polyaniline/styrene-acrylic acid copolymer systems: thermic and electric characterization. JNPN 4/3, 94-99 (2008).

49 Tsotra, P. \& Friedrich, K. Thermal, mechanical and electrical properties of epoxy resin/polyaniline-dodecylbenzenesulfonic acid blends. Synth. Met. 143, 237-242 (2004).

50 Cristiane, R. M. \& Marco, A. D. P. Antistatic thermoplastic blend of polyaniline and polystyrene prepared in a double-screw extruder. Eur. Polym. J. 41, 2867-2873 (2005).

51 Jyongsik, J., Joonwon, B. \& Kyungtae, L. Synthesis and characterization of polyaniline nanorods as curing agent and nanofiller for epoxy matrix composite. Polymer 46, 3677-3684 (2005). 